\title{
Arab Attitudes Toward Gender Roles: From Homogeneous Stereotype to Heterogeneous Reality
}

\section{Basem Al Atom ${ }^{a}$}

\begin{abstract}
Western society has historically perceived Arab attitudes toward gender roles in a stereotypically negative light. This perception has had great influence on international public opinion toward Arab treatment of women, Western foreign policy toward the Arab world and development aid programs in the Middle East. This paper seeks to question the legitimacy of this perception by advancing the hypothesis that Arab attitudes toward gender roles are heterogeneous rather than homogeneous. To do so, it uses cross-cultural analysis in examining survey data regarding women's status in the Arab world, the significance of which contributes to a more accurate and well-rounded understanding of Arab attitudes toward gender roles. Results confirm the hypothesis that Arab attitudes toward gender roles are heterogeneous rather than homogeneous. Indeed, contrary to the Western stereotype regarding Arab attitudes toward gender roles and Arab treatment of women, cross-cultural analysis of the statistical information provided showed that Arab societies differ from one another in their attitudes toward gender roles and that Arab states differ from one another in their governmental approaches to gender equality in terms of personal status laws, gender-based discrimination in the workplace, and overall policies aimed the advancement of women.
\end{abstract}

\section{Keywords}

Sociology, gender roles, Western stereotypes, Arab attitudes, status of women

The Western world has habitually presented Arab women as being oppressed within patriarchal Arab society. This stereotype is grounded within perceptions of the traditional gender role for women, described as being "based on rigid gender and generation hierarchies, with a woman's roles and identities restricted to those of child, adolescent, and then dependent wife and mother" (Kawar 1997: 4). Although this stereotype is common to the Western world as a whole, it has not always been applied in a blanket manner. In other words, levels of perceived oppression of Arab women fluctuate cross-culturally. For example, Western perceptions regarding the oppression of Jordanian women might give greater attention to the discrepancy between higher female educational attainment levels and lower female economic participation-oppression thus taking the form of a lack of opportunity for Jordanian women (Chamlou, Muzi, and Ahmed 2011: 3). Similarly, Western perceptions of the oppression of Saudi women might give greater attention to the idea of

aJordan University of Science and Technology, Jordan

\section{Correspondent Author:}

Basem Al Atom, Department of Humanities, Jordan University of Science and Technology, PO Box 3030, Irbid, Jordan, 22110

E-mail: basematom2000@yahoo.com 
Saudi women being forced to be veiled or being unable to drive (Ferraris 2015: 1). Additionally, Western perceptions of oppression toward Bedouin women might encapsulate all of the above within an even wider sphere of a general lack of social and economic opportunity (Abu-Rabia-Queder 2007: 1). Regardless of its fluctuating form as applied cross-culturally, however, the Western stereotype regarding Arab attitudes toward gender roles and Arab treatment of women remains essentially monolithic. A brief examination of the origins of this stereotype and its means of reinforcement is necessary before examining the legitimacy of its claims in light of cross-cultural survey data.

The Western stereotype regarding Arab attitudes toward gender roles is rooted in the perception that "Islam is oppressive toward women" (Public Broadcasting Service [PBS] 2002). Thus, Islam is perceived as a causal factor of women's oppression in the Arab world. Indeed, "Western publics, by lopsided margins, do not think of Muslims as 'respectful of women"” (Pew Research Center 2006). Additionally, Islam has been seen as "a culture in which women were the property of their fathers, brothers, uncles, grandfathers, or guardians" (Hirsi Ali 2006: 11). All of these perceptions are better understood at the backdrop of Huntington's dichotomy between Western civilization and the Arab world in his stating, "Western ideas of individualism, liberalism, constitutionalism, human rights, equality, liberty, the rule of law, democracy, free market, the separation of church and state, often have little resonance in Islamic, Confucian, Japanese, Hindu, Buddhist or Orthodox cultures" (Huntington 1993: 40). Some might argue, on the other hand, that Islam in fact served as a major source for reform, granting women rights that they previously did not have - namely, the right to choose their partner, the right to education, and the right to inherit (Pew Research Center 2006). However, regardless of the legitimacy of such a claim-i.e., that Islam is oppressive toward women-Islam undoubtedly serves as a causal factor of the Western stereotype regarding Arab attitudes toward gender roles. Moreover, this stereotype is at once monolithic and universally applied, albeit to greater and lesser degrees cross-culturally. Variations in cross-cultural application of the stereotype thus make sense, especially given the differing interpretations of women's rights in Muslim societies. Broadly speaking, for example, while most Muslim societies allow for women's social, economic, and political participation, others do not. Moreover, the factors involved in determining the degree of women's freedom in such areas often involve not only religion itself, but custom, family, and law. "In Saudi Arabia, for example, women vote, work, and have excellent access to education, but they must wear a restrictive veil and are prohibited from driving cars" (PBS 2002).

In addition to Islam being a causal factor of the Western stereotype regarding Arab attitudes toward gender roles and the treatment of women in the Arab World, the role of Western mainstream media cannot be overlooked in reinforcing such stereotypes. Not only does Western media representation of Arab women shed light on the factors that reinforce the Western stereotype, but they also illustrate - in line with the previously mentioned dichotomy advanced by Huntington-perceived differences in gender equality between both the Western and Arab worlds. Some have argued that issues related to Arab women were not of much interest to Western mainstream media prior to the attacks on the World Trade Center on September 11, 2001 (Al-Ariqi 2009: 4). This study takes the position, however, that although greater media attention may have been given to Arab women's issues post-9/11 than before, Western mainstream media has played a historically consistent role in reinforcing the stereotype that Arab women are oppressed. Indeed, Western media has chosen to habitually portray Arab women as oppressed and subordinate, thus failing to empower them (Abu-Rabia-Queder 2007: 96). Accordingly, 
Usage of women's bodies as sexual commodities or as a vehicle of sexual arousal was found to be the main negative image used... followed by an image of women who are in some way immoral. Other negative images included the portrayal of women as being illiterate, of limited intellectual capability, inexperienced, materialistic, opportunistic, weak, or dependent. (Allam 2008: 3)

Therefore, regardless of whether media representation of Arab women became greater post-9/11, it remains that Arab women have consistently been portrayed by Western mainstream media in a negative light, thus reinforcing the Western stereotype that Arab women are oppressed. As one author puts it, "A woman wearing a veil has now become the symbol of women in the Arab world" (Abu-Rabia-Queder 2007: 96). Having established that Islam is a causal factor and Western mainstream media is a reinforcer of the Western stereotype regarding Arab attitudes toward gender roles and Arab treatment of women, this paper seeks to address the following question: How much does the Western stereotype regarding Arab attitudes toward gender roles and Arab treatment of women reflect the real and diverse situations of women in the Arab world?

\section{METHODOLOGY}

\section{Design}

Cross-cultural analysis was employed in examining statistical data provided by the Thomas Reuters Foundation's poll in 2013 titled "Women's Rights in the Arab World". Kinzer and Gillies define cross-cultural analysis's "basic premise (as) statistical cross-cultural comparisons... used to discover traits shared between cultures (in order to) generate ideas about cultural universals" (Al-Ariqi 2009: 1).

\section{Sample}

Human rights, humanitarian, and development organizations at the international, regional, national, and local levels, healthcare service providers, refugee agencies, media conglomerates, legal activists and advisers, media-involved professionals and academics were targeted, with special attention given to respondents who are female.

\section{Scope}

Data illustrating women's rights' perceptions in all 22 member states of the Arab League were examined. These include United Arab Emirates (UAE), Yemen, Tunisia, Palestine, Sudan, Somalia, Saudi Arabia, Qatar, Oman, Morocco, Mauritania, Libya, Lebanon, Kuwait, Jordan, Iraq, Egypt, Djibouti, Comoros, Bahrain, and Algeria.

\section{Questionnaire}

The following six Convention on the Elimination of All Forms of Discrimination Against Women (CEDAW)-based articles formulated the basis of the questionnaire: violence against women, reproductive rights, women in the family, women in the economy, women in society, and women in politics. "Violence against women" involves the most heinous abuses of violence as documented among all 22 member states of the Arab League. These include marital rape, corporal punishment, female genital mutilation, and trafficking. "Reproductive rights" involves attitudes toward women's choice in child-bearing and reproductive healthcare access. "Women in the family" involves issues relating to women's choice in choosing their marriage partner, including the right to divorce. "Women in the economy" refers to women's financial self-sustainability, including discrimination in the workplace. "Women in society" refers to sociocultural attitudes toward women, particularly those that debilitate women's economic participation. "Women in politics" involves governmental representation of women.

\section{Description of Participants}

The questionnaire was distributed in a manner that protects the privacy of the participants. Namely, 
Table 1. "Violence Against Women": State Comparison

\begin{tabular}{lll}
\hline Country & Ranking & Score (from worst to best) \\
\hline Egypt & 22 & 20.374 \\
Iraq & 21 & 18.623 \\
Sudan & 20 & 18.413 \\
Yemen & 19 & 18.112 \\
Djibouti & 18 & 17.408 \\
Saudi Arabia & 17 & 17.408 \\
Somalia & 16 & 17.207 \\
Syria & 15 & 16.93 \\
Lebanon & 14 & 16.516 \\
Bahrain & 13 & 16.191 \\
Mauritania & 12 & 16.067 \\
UAE & 11 & 15.788 \\
Oman & 10 & 15.481 \\
Libya & 9 & 14.868 \\
Qatar & 8 & 14.758 \\
Palestine & 7 & 14.673 \\
Kuwait & 6 & 14.446 \\
Morocco & 5 & 14.216 \\
Jordan & 4 & 13.716 \\
Tunisia & 3 & 12.883 \\
Comoros & 2 & 12.789 \\
Algeria & 1 & 12.617 \\
\hline
\end{tabular}

internet tracking devices such as "cookies" were disabled in order to allow participants to answer the questionnaire without being inhibited by fears of government surveillance. At least 10 participants took part from each of the 22 members states of the Arab League. Incomplete responses were omitted and "country scores" were gathered by arranging data responses by theme. Higher scores illustrated worse situations for women while lower scores illustrated better situations for women.

\section{RESULTS}

\section{Violence Against Women}

Issue 1 in Table 1 dealt with the commonality of female genital mutilation practices in the respective states. Comoros, Tunisia, Morocco, Syria, Algeria, Jordan, and Kuwait ranked the best in terms of consisting of the least amount of commonality with regard to female genital mutilation. Egypt, Djibouti, Somalia, Mauritania, Sudan, and Oman ranked the worst. Issue 2 dealt with marital rape-namely, whether respondents believed that marital rape is punishable by law. Mauritania, Comoros, Algeria, Jordan, and Tunisia ranked the best, while Bahrain, Lebanon, Saudi Arabia, Yemen, and Egypt ranked the worst. Issue 3 dealt with participants' belief as to whether female trafficking occurs or has a greater likelihood of occurring in their respective countries. Libya, Algeria, Palestine, Jordan, and Kuwait ranked the best, while Egypt, Iraq, Yemen, Syria, and Mauritania ranked the worst. Issue 4 dealt with the 
Table 2. "Reproductive Rights": State Comparison

\begin{tabular}{lll}
\hline Country & Ranking & Score (from worst to best) \\
\hline Egypt & 22 & 11.294 \\
Lebanon & 21 & 11.055 \\
Syria & 20 & 10.538 \\
Sudan & 19 & 10.39 \\
Palestine & 18 & 10.217 \\
Iraq & 17 & 10.021 \\
Saudi Arabia & 16 & 10.002 \\
Morocco & 15 & 9.934 \\
Somalia & 14 & 9.924 \\
UAE & 13 & 9.604 \\
Jordan & 12 & 9.558 \\
Yemen & 11 & 9.448 \\
Bahrain & 10 & 9.227 \\
Kuwait & 9 & 9.225 \\
Tunisia & 8 & 8.864 \\
Algeria & 7 & 8.703 \\
Qatar & 6 & 8.636 \\
Oman & 5 & 8.488 \\
Libya & 4 & 8.415 \\
Djibouti & 3 & 8.271 \\
Mauritania & 2 & 8.25 \\
Comoros & 1 & 6.931 \\
\hline
\end{tabular}

issue of motivators with regard to violence against women along the following lines: perpetrator impunity, lack of social repercussions for violence against women, lack of proper protection for victims of violence or rape, lack of access to police-reporting mechanisms and acceptability of honor killings. Mauritania, Djibouti, Oman, Kuwait, and Qatar ranked the best, while Saudi Arabia, Libya, Iraq, Egypt, and Syria ranked the worst.

\section{Reproductive Rights}

Issue 1 in Table 2 dealt with whether pregnant women who are employed felt that they would be targeted for dismissal as a result of their pregnancy and employer obligations regarding benefits for pregnant employees. Comoros, Libya, Qatar, Oman, and Djibouti ranked the best, while Lebanon, Egypt, Morocco, Iraq, and Syria ranked the worst. Issue 2 dealt with women's control over their family planning abilities. Comoros, Tunisia, Oman, Bahrain, and Libya ranked the best, while Sudan, Egypt, Syria, UAE, and Somalia ranked the worst. Issue 3 dealt with participants' opinions regarding the importance of addressing the following issues regarding reproduction: reproductive education access, birth control access, pre-natal care and post-natal care access, and safe and legal abortion access. Mauritania, Djibouti, Jordan, UAE, and Algeria ranked the best, while Egypt, Saudi Arabia, Lebanon, Syria, and Palestine ranked the worst.

\section{Women in the Family}

Issue 1 in Table 3 dealt with whether participants view personal status laws as biased against women. Jordan, Somalia, Comoros, Morocco, and Libya ranked the best, while Syria, Saudi Arabia, Lebanon, Djibouti, and Tunisia ranked the worst. Issue 2 dealt with 
Table 3. "Women in the Family": State Comparison

\begin{tabular}{lll}
\hline Country & Ranking & Score (from worst to best) \\
\hline Syria & 22 & 11.872 \\
Iraq & 21 & 11.844 \\
Saudi Arabia & 20 & 11.579 \\
Egypt & 19 & 11.306 \\
Yemen & 18 & 11.217 \\
Sudan & 17 & 10.824 \\
Lebanon & 16 & 10.772 \\
Palestine & 15 & 10.738 \\
Djibouti & 14 & 10.319 \\
Kuwait & 13 & 10.2 \\
Oman & 12 & 9.955 \\
UAE & 11 & 9.897 \\
Tunisia & 10 & 9.871 \\
Qatar & 9 & 9.849 \\
Bahrain & 8 & 9.764 \\
Libya & 7 & 9.706 \\
Algeria & 6 & 9.668 \\
Mauritania & 5 & 9.244 \\
Morocco & 4 & 9.045 \\
Jordan & 3 & 8.769 \\
Somalia & 2 & 8.759 \\
Comoros & 1 & 7.775 \\
\hline
\end{tabular}

whether participants felt that women who refuse to enter into arranged marriages were prone to physical and mental abuse. Bahrain, Somalia, Lebanon, Qatar, and Morocco ranked the best, while Iraq, Yemen, Syria, Egypt, and Saudi Arabia ranked the worst. Issue 3 dealt with participants' ranking of the following factors related to divorce: women's loss or assets and property, dowry reimbursement, psychological or physical abuse, fear of being ostracized and fear of being refused permission by her husband. Comoros, Tunisia, Djibouti, Mauritania, and Algeria ranked the best, while Syria, Iraq, Saudi Arabia, Egypt, and Lebanon ranked the worst.

\section{Women in the Economy}

Issue 1 in Table 4 dealt with whether participants believed workplace discrimination is appropriately punished. Iraq, Somalia, Mauritania, Jordan, and Oman ranked the best, while Algeria, Egypt, Bahrain, Djibouti, and Palestine ranked the worst. Issue 2 dealt with whether participants believed that if a woman becomes a widow, she loses her property unless she marries a close relative of her former husband. Comoros, Bahrain, Tunisia, Morocco, and Mauritania ranked the best, while Palestine, Djibouti, Sudan, Egypt, and Iraq ranked the worst. Issue 3 dealt with participants' ranking of the following impediments to women's ownership of private property: lack of credit access, lack of employment as a result of discrimination, religion, and customs, societal opposition to the ownership of private property by women and personal status laws. Comoros, Kuwait, Oman, Qatar, and Morocco ranked the best, while Saudi Arabia, Iraq, Syria, Yemen, and Sudan ranked the worst. 


\section{Women in Society}

Issue 1 in Table 5 dealt with whether participants believed that girls are expected by society to cease education sooner than boys. Bahrain, Qatar, Oman, Kuwait, and Lebanon ranked the best, while Iraq, Yemen, Syria, Sudan, and Somalia ranked the worst. Issue 2 dealt with whether girls felt pressured to get married before turning 18. Bahrain, Qatar, Algeria, Tunisia, and Comoros ranked the best, while Iraq, Sudan, Yemen, Syria, and Mauritania ranked the worst. Issue 3 dealt with participants' ranking of the following factors regarding women's social and political opportunities: lack of equality in home life between men and women, lack of equality regarding training and education, lack of governmental mechanisms capable of promoting women's advancement, lack of freedom to travel for women, and lack of access to the internet and other means of communication. Kuwait, UAE, Qatar, Bahrain, and Comoros ranked the best, while Syria, Iraq, Saudi Arabia, Sudan, and Somalia ranked the worst.

\section{Women in Politics}

Issue 1 in Table 6 dealt with whether participants believe that women and men enjoy equal opportunities to run for elected office. Oman, Libya, Mauritania, Qatar, and Jordan ranked the best, while Saudi Arabia, Bahrain, Yemen, Egypt, and Somalia ranked the worst. Issue 2 dealt with whether participants believe that the government has worked positively to get rid of laws that discriminate against women. Comoros, Djibouti, Kuwait, Morocco, and Qatar ranked the best, while Saudi Arabia, Bahrain, Egypt, Lebanon, and Yemen ranked the worst. Issue 3 dealt with participants' beliefs regarding the greatest challenges to gender equality in government and politics, along the following lines: societal stereotypes about what women cannot and can do, lack of gender equality-specific legal codes, i.e., laws that specifically express gender equality, the impact of conservative religion, lack of government condemnation toward discrimination based on gender and lack of freedom of association and movement. Comoros, Djibouti, Jordan, Morocco, and Oman ranked the best, while Saudi Arabia, Iraq, Egypt, Libya, and Syria ranked the worst.

\section{CONCLUSIONS}

The above results serve to confirm the hypothesis of this study, namely-Arab attitudes toward gender roles are heterogeneous rather than homogeneous. Indeed, contrary to the Western stereotype regarding Arab attitudes toward gender roles and Arab treatment of women, cross-cultural analysis of the statistical information provided showed that Arab societies differ from one another in their attitudes toward gender roles and that Arab states differ from one another in their governmental approaches to gender equality in terms of personal status laws, gender-based discrimination in the workplace, and overall policies aimed at the advancement of women. This is not to say that the Western stereotype is completely wrong in asserting that gender-based discrimination exists in the Arab world. Indeed, just as in all regions of the world, gender-based discrimination does indeed exist in Arab states. Egypt, for example, was rated as illustrating the worst situation for women in the Arab world according to experts polled. This is particularly the case due to its governmental policies and societal attitudes toward sexual harassment and female genital mutilation. Regarding general harassment, Iraq placed second in line with Egypt. Yemen, Syria, and Saudi Arabia followed suit. Egypt was also ranked highest for trafficking of women and laws that are discriminatory toward women. This study does assert, however, that the Western stereotype is wrong in its blanket assumptions regarding the degree of such discrimination in the Arab world. In line with the previous assertion that the factors involved in determining the degrees of women's freedom include 
Table 4. "Women in the Economy": State Comparison

\begin{tabular}{lll}
\hline Country & Ranking & Score (from worst to best) \\
\hline Palestine & 22 & 10.682 \\
Saudi Arabia & 21 & 10.196 \\
Syria & 20 & 9.995 \\
Egypt & 19 & 9.955 \\
Djibouti & 18 & 9.844 \\
Yemen & 17 & 9.838 \\
Sudan & 16 & 9.765 \\
Lebanon & 15 & 9.351 \\
Iraq & 14 & 9.328 \\
Algeria & 13 & 9.129 \\
Jordan & 12 & 8.926 \\
Libya & 11 & 8.922 \\
Qatar & 10 & 8.749 \\
UAE & 9 & 8.688 \\
Tunisia & 8 & 8.611 \\
Somalia & 7 & 8.486 \\
Bahrain & 6 & 8.48 \\
Morocco & 5 & 8.289 \\
Mauritania & 4 & 8.283 \\
Kuwait & 3 & 8.125 \\
Oman & 2 & 7.902 \\
Comoros & 1 & 7.424 \\
\hline
\end{tabular}

Table 5. "Women in Society": State Comparison

\begin{tabular}{lll}
\hline Country & Ranking & Score (from worst to best) \\
\hline Iraq & 22 & 11.847 \\
Syria & 21 & 11.619 \\
Sudan & 20 & 11.487 \\
Yemen & 19 & 11.207 \\
Somalia & 18 & 10.403 \\
Mauritania & 17 & 10.226 \\
Saudi Arabia & 16 & 9.934 \\
Palestine & 15 & 9.92 \\
Egypt & 14 & 9.872 \\
Morocco & 13 & 8.898 \\
Djibouti & 12 & 8.816 \\
Libya & 11 & 8.717 \\
Jordan & 10 & 8.23 \\
Comoros & 9 & 8.05 \\
Algeria & 8 & 7.884 \\
Tunisia & 7 & 7.851 \\
Lebanon & 6 & 7.784 \\
Oman & 5 & 7.603 \\
UAE & 4 & 7.297 \\
Kuwait & 3 & 7.03 \\
Qatar & 2 & 6.968 \\
Bahrain & 1 & 6.31 \\
\hline & & \\
\hline
\end{tabular}


Table 6. "Women in Politics": State Comparison

\begin{tabular}{lll}
\hline Country & Ranking & Score (from worst to best) \\
\hline Saudi Arabia & 22 & 13.752 \\
Bahrain & 21 & 12.275 \\
Egypt & 20 & 12.094 \\
Yemen & 19 & 12.04 \\
Lebanon & 18 & 11.453 \\
Syria & 17 & 11.436 \\
Iraq & 16 & 11.407 \\
Algeria & 15 & 11.129 \\
Somalia & 14 & 11.077 \\
Sudan & 13 & 10.807 \\
Libya & 12 & 10.469 \\
Tunisia & 11 & 110.465 \\
Palestine & 10 & 10.399 \\
UAE & 9 & 10.208 \\
Morocco & 8 & 9.847 \\
Mauritania & 7 & 9.42 \\
Qatar & 6 & 9.412 \\
Kuwait & 5 & 9.093 \\
Jordan & 4 & 9.019 \\
Oman & 3 & 8.652 \\
Comoros & 2 & 8.406 \\
Djibouti & 1 & 8.262 \\
\hline
\end{tabular}

not only religion itself, but custom, family, and law, the data show that contrary to the idea of Islam legitimately being a causal factor of the Western stereotype, most Islamic countries in fact work actively toward the advancement of women. For example, while Saudi Arabia ranked low in terms of women's political participation, gender-based discrimination in the workplace, and freedom of association and movement, it ranked higher than other states in terms of healthcare and education, gender violence, and reproductive rights. Comoros undoubtedly ranked highest in terms of women's situation in the Arab world, however, with Qatar, Kuwait, Oman, and Jordan following suit. All of these illustrations reflect the diverse attitudes toward gender roles in the Arab World and thus contradict the Western stereotype's blanket assumption that all Arab women are oppressed in all Arab states. Perhaps such a diverse reflection of women's varying situations in the Arab world will contribute to a more accurate and well-rounded understanding of Arab attitudes toward gender roles.

\section{References}

Abu-Rabia-Queder, S. 2007. "The Activism of Bedouin Women: Social and Political Resistance." HAGAR Studies in Culture, Polity and Identities 7(2):67-84.

Al-Ariqi, A. 2009. Middle Eastern Women in the Media: A Battle Against Stereotypes. Al Jazeera: A Case Study. Reuters Institute for the Study of Journalism. Retrieved (http://reutersinstitute.politics.ox.ac.uk/sites/default/files/Mi ddle\%20Eastern\%20Women\%20in\%20the\%20Media $\% 20$ A\%20Battle\%20Against\%20Stereotypes.pdf).

Allam, R. 2008. "Countering the Negative Image of Arab Women in the Arab Media: Towards a Pan Arab Eye." The Middle East Institute Policy Brief. Retrieved (http://www. mei.edu/content/countering-negative-image-arab-women-ar ab-media-toward-pan-arab-eye-media-watch-project).

Chamlou, N., S. Muzi, and H. Ahmed. 2011. Understanding the Determinants of Female Labor Force Participation in 
Middle East and North Africa Region: The Role of Education and Social Norms in Amman. Washington, D.C.: World Bank.

Ferraris, R. 2015. "Dispelling a Stereotype: Women in the Gulf." Mail \& Guardian. Retrieved (http://www. thoughtleader.co.za/readerblog/2012/04/17/dispelling-a-ster eotype-women-in-the-arab-gulf/).

Hirsi Ali, A. 2006. The Caged Virgin: An Emancipation Proclamation for Women and Islam. New York: Free Press.

Huntington, S. P. 1993. "The Clash of Civilizations?" Foreign Affairs 72(3):40.

Kawar, M. 1997. "Gender and Generation in Household Labor Supply in Jordan.” PhD research project, London School of Economics.

Nawar, I. 2007. "Portraying Women in the Western and Arab Media-General Remarks. Mass Media and Mutual Perception." Quaderns de la Mediterrania (Journal of the Meditarranean) 8:95-98.

Pew Research Center. 2006. The Great Divide: How Westerners and Muslims View Each Other. Retrieved April 3, 2014 (http://www.pewglobal.org/2006/06/22/the-greatdivide-how-westerners-and-muslims-view-each-other/).
Public Broadcasting Service (PBS). 2002. What Are Some Typical Misperceptions and Stereotypes Westerners Hold About Islam and the Middle East, and Vice Versa? Retrieved April 3, 2014 (http://www.pbs.org/wgbh/ globalconnections/mideast/questions/types/index.html?page wanted=all).

Thomas Reuters Foundation. 2013. Women's Rights in the Arab World. Retrieved April 3, 2014 (http://www. trust.org/spotlight/poll-womens-rights-in-the-arab-world/).

UNESCO (United Nations Educational, Scientific, and Cultural Organization). 2004. In a symposium “Arab Woman Between East and West", organized in the framework of UNESCO's Arabia Plan. Paris.

\section{Bio}

Basem Al Atom, Ph.D., associate professor, Department of Humanities, Jordan University of Science and Technology; research fields: culture and university behavior, environmental sociology, individual and society, international global issues, principles of sociology, and sociology. 